\title{
Quantitative Electroencephalography for Objective and Differential Diagnosis of Depression: A Comprehensive Review
}

\author{
Ali Yadollahpour ${ }^{1} \&$ Hadi Nasrollahi $^{1}$ \\ ${ }^{1}$ Department of Medical Physics, School of Medicine, Ahvaz Jundishapur University of Medical Sciences, \\ Ahvaz, Iran \\ Correspondence: Ali Yadollahpour, Assistant Professor of Medical Physics, Department of Medical Physics, \\ School of Medicine, Ahvaz Jundishapur University of Medical Sciences, Golestan Blvd., Ahvaz 61357-33118, \\ Iran. Tel: 98-613-333-0074. E-mail: yadollahpour.a@gmail.com
}

Received: February 3, 2016 Accepted: March 21, 2016 Online Published: March 31, 2016

doi:10.5539/gjhs.v8n11p249 URL: http://dx.doi.org/10.5539/gjhs.v8n11p249

\begin{abstract}
Quantitative electroencephalography (QEEG) has been dramatically developed during recent years in cognitive neurosciences. It has shown significant potential in the diagnosis of cognitive neurological disorders as well as in the evaluation of treatment outcomes and response. Early diagnosis of depression, differential diagnosis, and assessing the treatment outcomes and response are currently the main research fields of QEEG in depression. Identifying reliable disorder-specific EEG-based biomarkers that have strong correlations with the depression specific cognitive functions is one of the major challenges in these fields. Such biomarkers not only allow early and cost-effective diagnosis of depression, but also may have differential diagnostic and predictive values for treatment response of a variety of treatments. This paper aims at a comprehensive review on the main principles of QEEG in developing biomarkers for MDD. The databases of PubMed (1985-2015), Web of Sciences (1985-2015), and Google Scholar (1980-2015) were searched using the set terms. The obtained results were screened for the title and abstract by two authors and they came to consensus whether the studies are related to the review. The main advantages of QEEG for mood disorders are also reviewed. In addition, different QEEG-based measures for objective diagnosis of MDD as well as for distinguishing depressed patients from healthy subjects are discussed.
\end{abstract}

Keywords: major depressive disorder, depression, EEG biomarker index, QEEG, objective diagnosis, differential diagnosis

\section{Introduction}

Depression is among the most common psychiatric disorders worldwide, affected more than 350 million people (Lépine \& Briley, 2011). Its symptoms include fatigue, boredom, sleeplessness, suicidal thoughts, suicide attempts, digestive problems, frustration, anger, loss of sexual desire, isolation, lack of concentration, and memory loss (Lépine, 2000; Marcus, Yasamy, van Ommeren, Chisholm, \& Saxena, 2012). In addition to these symptoms, recent studies and functional imaging techniques have shown that different regions of the brain of depression patients undergo significant physiological and functional changes (Anderson et al., 2002; Koolschijn et al., 2009; Kwon, Youn, \& Jung, 1996). These symptoms affect various physiological and psychological, personal, and social aspects of human life so that making the treatment of depressive disorders as one of the world's most expensive medical treatments (Ali \& Mahmud, 2014; Health, 2010; Lépine \& Briley, 2011; Von Korff et al., 1998). Effective pharmaceutical or alternative treatments such as electrical and magnetic stimulations for depression require early diagnosis of depression. On one hand, depressive disorders have different subcategories of disorders including bipolar, major, and seasonal depressions with similar clinical and behavioral symptoms, so that conventional psychometric questionnaires such as Beck depression inventory (BDI) and Hamilton Depression Rating Scale (HDRS) are not capable of a specific differential diagnosis (Beck, Steer, $\&$ Carbin, 1988). On the other hand, depression is also accompanied with other psychological and physiological disorders, which makes disease-specific and differential diagnosis of the depression against other psychological disorders difficult. Therefore, developing objective, sensitive, disease-specific, and differential diagnostic techniques are necessary for more efficient management of depressive disorders.

Psychometric questionnaires and interviews with the patients are mostly used for diagnosis and classification of 
depressive disorders (Beck et al., 1988; Health, 2010). These diagnostic techniques suffer different drawbacks which are associated with significant bias and inaccuracy. Subjective assessment, dependency of the tests' results to the mood of the patients, as well as to the interviewer or physician are some of these drawbacks (Goldberg, Bridges, Duncan-Jones, \& Grayson, 1988; Snaith, Ahmed, Mehta, \& Hamilton, 1971). In this regard, new objective techniques have been developed for diagnosis of depression. During recent years different anatomical, metabolic, and physiological based techniques have been developed for this purpose. These techniques have proposed different measures for objective and quantitative diagnosis of MDD. Quantitative EEG (QEEG) is a promising technique for objective, differential diagnosis, and treatment response assessment of psychiatric disorders such as depression (Arns \& Gordon, 2014; Begić, Hotujac, \& Jokić - Begić, 2000; Begić et al., 2011).

Currently, various studies are ongoing to find reliable new QEEG-based measures for objective and differential diagnosis of depression and for assessing treatment outcomes (Hunter, Muthén, Cook, \& Leuchter, 2010). The present study reviews the main principles of QEEG, its clinical and research applications in depression including objective and differential diagnosis. In addition, the main QEEG based measures that have been reported as indicative of depressive disorders are reviewed.

\section{Method}

The databases of PubMed (1985-2015), Web of Sciences (1985-2015), and Google Scholar (1980-2015) were searched using the following keywords: "depression" or "major depressive disorder" and "EEG", "QEEG", "electroencephalogram", and "diagnosis". The obtained results were screened for the title and abstract by two authors and they came to consensus whether the studies are related to the review. Because of the immense body of literature in this field, this study was not aimed to provide a systematic review; but it provides a comprehensive and descriptive overview of principles of QEEG in developing biomarkers for MDD. In addition, the different QEEG-based measures for objective diagnosis of MDD as well as for distinguishing depressed patients from healthy subjects.

\section{Results}

\subsection{QEEG and Depression Objective Diagnosis}

During recent years anatomical, metabolic, and physiological based techniques have proposed different measures for objective and quantitative diagnosis of MDD. Decreased cortical volumes in prefrontal brain areas such as the dorsolateral prefrontal cortex (DLPFC) or the subgenual gyrus (Bremner et al., 2002; Koolschijn et al., 2009), reduced hippocampal volume (Frodl et al., 2006), decreased orbitofrontal volume (Bremner et al., 2002; Koolschijn et al., 2009), altered connectivity and activity in frontal and anterior cingulate cortex (ACC) networks (Johansen-Berg et al., 2008), altered inflammatory cytokine and growth factor levels (Deschwanden et al., 2011; Miller, Maletic, \& Raison, 2009; Raison, Capuron, \& Miller, 2006) are some of these measures. However, these measures have not been entered into routine clinical prognostic applications. The main issues of these measures are low availability of the corresponding techniques in routine clinical setting, low specificity, low sensitivity, and inter-individual heterogeneity of the measures.

EEG is a low-cost, non-invasive, and widely available technique with good temporal and spatial resolution. EEG provides a temporal resolution in a time scale of milliseconds, which is the time-frame at which neuronal activity, and especially cognition, takes place. EEG directly measures and presents the ongoing electric activity from the brain that makes this technique a valuable complementary brain imaging method (He, Lian, \& Li, 2001; Teplan, 2002). These features make EEG as one of the most reliable sources of biomarker research.

EEG is currently used in different clinical settings for routine diagnostic purposes. Current evidence demonstrates high reliability and sensitivity of QEEG in diagnosing some psychological and neurophysiological disorders such as epileptic foci, depression, ADHD (Roemer, Shagass, Dubin, Jaffe, \& Siegal, 1992; Sulg, 1984). QEEG in combination with neuro-modulation techniques, techniques involving electrical and magnetic stimulation to alter the neural activities, have been used for early diagnosis or prediction of disease status (Norouzi, Yadollahpour, Mirbagheri, Mazdeh, \& Hosseini, 2016; YADOLLAHPOUR, 2014; YADOLLAHPOUR \& JALILIFAR, 2014), modulating neurophysiological functions (Ali \& Mahmud, 2014; ALI, MAHMUD, \& SAMANEH, 2015), and developing brain-machine interface protocols (ALI \& Abdolhossein, 2014). QEEG is a computational analysis of a conventional EEG wave to represent the neural activities in numeral format and various parameters like frequency and amplitudes (Roemer et al., 1992; Sulg, 1984; Teplan, 2002). Using QEEG we can demonstrate the conventional EEG into electroencephalographic maps which are functional mapping of the brain. Various studies have been carried out to find the QEEG based measures that are depression-specific. Power, asymmetry, coherence, and cordance of EEG signals in different regions of the brain are some of these measures. 


\subsection{QEEG Measures Specific of Depression}

Upon the introduction of QEEG in the late 1980s, the American society of clinical EEG and QEEG committee indicated QEEG as a valuable diagnostic technique. Various surveys have indicated the efficacy of QEEG in clinical and basic research applications.

The EEG is composed of synchronized synaptic and membrane potentials in the cerebral cortex which are recorded as continuous waves (EEG signals) made up of different frequencies and rhythms. The EEG of healthy adults in different behavioral conditions contains typical frequencies and amplitude features (Begić, Hotujac, \& Jokić-Begić, 2001; Olbrich et al., 2012). Accordingly, the EEG of adults suffering a disease affecting the functions of central nervous system shows patterns different from healthy counterparts so that these patterns are specific to the disease.

The EEG of adults in a waking state consists mainly of alpha waves in the $8-13 \mathrm{~Hz}$ frequency range and some beta waves in the $14-30 \mathrm{~Hz}$ frequency range, while there are few theta waves in the $4-7 \mathrm{~Hz}$ frequency range, and almost no visible delta waves in the $0.5-3 \mathrm{~Hz}$ frequency range. During drowsiness and sleep, the EEG of adults consists of more slow (low frequencies) waves.

In depressed patients left DLPFC shows hypoactivation, characterized by relatively higher left alpha activity, while right DLPFC shows hyperactivation which is manifested by relatively lower right alpha activity. Recent studies have reported some QEEG-based measures as indicative of depression.Some of these measures are (1) The difference in theta power in the frontal areas, (2) left-to-right asymmetric index, (3) different powers of the alpha, and beta bands in frontal lobe in depressed patients are different with healthy peers. However, no relationship between depression severity and EEG asymmetry has been reported. In addition, absolute and relative power in the beta band appeared to differentiate depressed patients and healthy counterparts where patients show more beta power than healthy subjects. In addition, decreasing frontal alpha asymmetry has been reportedly as an index of recovering from depression. QEEG and LORETA (low-resolution electromagnetic tomography) have shown that alpha left-to-right asymmetries of the depressed patients are higher than the healthy subjects. These asymmetries have been observed for central, temporal, superior frontolateral and medial regions of two hemispheres. For example, the depressed patients have increased alpha current density in the left hemisphere compared to the right hemisphere (Allen, Urry, Hitt, \& Coan, 2004; Deslandes et al., 2008; Gordon, Palmer, \& Cooper, 2010; V. Knott, Mahoney, Kennedy, \& Evans, 2001). These differences were because that in the healthy subjects a balance of the metabolic and physiologic functions between the left and right hemispheres exist which is manifested in inhibiting-facilitating circuits. This balance in depression is disturbed and depending on the region we observe left-to right asymmetries of the two hemispheres. However, some other studies have reported an increased source-current density of the right hemisphere in the delta, alpha, and beta frequency bands in depressed patients compared with healthy individuals (Carvalho et al., 2011; Ricardo-Garcell et al., 2009). Further studies are needed to shed more light on the exact relationship between the two hemispheric asymmetrical indexes of different EEG bands and the status and severity of MDDs.

\subsection{QEEG in Distinguishing Depressed from Healthy Subjects}

The onset of clinical manifestations of depression is usually at mild to severe stages of the disorder which make the conventional treatments difficult and even sometimes non-efficient (Lieber, 1988; Lieber \& Prichep, 1988). For an efficient treatment, early and reliable diagnosis of MDDs is necessary. Currently, psychometric questionnaires are the gold standard techniques for diagnosis of MDDs. These tools evaluate the behavioral and cognition based criteria to diagnose the disease. However, developing MDDs, early stages of disease, are associated with neurophysiologic and metabolic alterations which are followed by cognitive alterations along with the development of the disease. Using appropriate techniques to measure such measures associated with early stages of the disease is a crucial step for developing a technique for early diagnosis of the disease. QEEG is such technique capable of measuring and quantifying neurophysiologic alterations (Lieber, 1988; Lieber \& Prichep, 1988). In addition, various studies have shown therapeutic delay in antidepressant action of the most of antidepressant medications(Papakostas \& Fava, 2008; Sackeim, Roose, \& Burt, 2005). Furthermore, some of antidepressants have reportedly shown their therapeutic effects selectively or on the other hand some depressed patients show selective response to common antidepressants. Therefore, developing reliable measure for early diagnosis of depressive disorders or differential diagnosis of depressed patients from healthy individuals is of clinical importance.

EEG data contain information about neural activities of different regions of brain at different frequencies. Several EEG-based measures have been proposed for distinguishing the MDD and healthy subjects such as QEEG, EEG source estimates, left/right hemispheric alpha, beta, and delta asymmetry EEG, non-linear and 
linear coherence, EEG vigilance, EEG cordance, event related potentials, and sleep EEG.

Time series analysis methods such as Fourier transformation can also be used to assess the EEG and to reliably separate different components such as the power of the main frequency bands: delta $(1-3 \mathrm{~Hz})$, theta $(4-7 \mathrm{~Hz})$, alpha $(8-12 \mathrm{~Hz})$, and beta $(13-25 \mathrm{~Hz})$. Increased EEG alpha activity during rest in depressed patients is one of the most consistent findings reported by recent studies. This increase was reported either in absolute alpha power or in relative power (Bruder et al., 2008; Debener et al., 2000; Gordon et al., 2010; Zoon et al., 2013). Increases were mainly located to parietal and frontal or occipital sites (Bruder et al., 2008; Debener et al., 2000; Deslandes et al., 2008). In a large sample size study, increased alpha as well as theta activities were reported in patients in early stages of depression (Grin-Yatsenko, Baas, Ponomarev, \& Kropotov, 2010). However, some other studies have reported no alpha power differences between MDD patients and healthy controls (V. Knott et al., 2001). In addition, some studies have demonstrated decreased relative alpha activity in MDD patients compared with healthy counterparts (Pozzi, Golimstock, Petracchi, García, \& Starkstein, 1995). These contradictory findings are likely because the MDD patients may have other disorders such as dementia or other psychiatric disorders including anxiety and stress. Accordingly, studies on this topic should subgroup MDD into different categories. Further studies have shown that patients with excess alpha generally show better respond to antidepressive treatments (Ulrich, Renfordt, Zeller, \& Frick, 1984). On the other hand, post-intervention recordings of EEG have shown that antidepressants decrease alpha power in MDD patients (Itil, 1982) which support the important role of alpha rhythm in at least a subgroup of MDD patients.

In addition to alpha power, several studies have highlighted increased slow wave activity as an indicator of MDD (Kwon et al., 1996; Lieber, 1988; Lieber \& Prichep, 1988); Roemer et al., 1992). However, some studies on identification of QEEG-based measures as a treatment-response predictor in MDD have reported that excess theta activity is associated with non-response to antidepressant treatments (Bares et al., 2008; Iosifescu et al., 2009; V. J. Knott, Telner, Lapierre, Browne, \& Horn, 1996; Arns, Drinkenburg, Fitzgerald, \& Kenemans, 2012). Among the fast frequencies, some studies have demonstrated that increased beta range activity is correlated with depression severity (Knott et al., 2001; Lieber, 1988; Lieber \& Prichep, 1988). One of the main challenging issues in developing QEEG in objective and differential diagnosis of depressive disorders is limitations of comparisons between different topographic EEG studies due to different references or montages. To overcome this challenge, some approaches have been proposed such as LORETA which determines intracortical EEG sources (Jaworska, Blier, Fusee, \& Knott, 2012; Korb, Cook, Hunter, \& Leuchter, 2008; Mientus et al., 2002). This technique has been used to provide more robust and complementary measures for objective and differential diagnosis of MDDs (Mientus et al., 2002; Mulert, Juckel, Augustin, \& Hegerl, 2002; Saletu, Anderer, \& Saletu-Zyhlarz, 2010). For the future, non-linear time series analysis of EEG in combination with source density estimation techniques and neuro-imaging modalities can significantly develop the objective and differential diagnosis of MDDs. In addition, developing some techniques to identify those patients who either respond or do not respond the treatment has been always of scientific interest. In this regard, some studies have attempted to extract some biomarkers, extracted from EEG of patients, which are associated with responding or not responding to the treatment like transcranial magnetic stimulation and medications. Recent studies have reported that some EEG based indices can appropriately distinguish responders from non-responders before or soon after intervention administration (Arns et al., 2012; Cook \& Leuchter, 2001; Funk \& George, 2008; V. J. Knott et al., 1996; Mulert et al., 2007). The early studies have shown promising potential of QEEG for treatment-response predicting which can significantly improve the treatment and management of the MDDs.

\section{Conclusions}

Present study overviewed the main principles of QEEG, its clinical and research applications in depression such as objective and differential diagnosis. Different QEEG based measures have been introduced for objective and early diagnosis MDDs, for differential diagnosis of depressed patients from healthy individuals, as well as for predicting response or non-response to antidepressant agents. Some of the main EEG extracted measures in these fields are EEG source estimates, left/right hemispheric alpha, beta, and delta asymmetry EEG, non-linear and linear coherence, EEG vigilance, EEG cordance, event related potentials, and sleep EEG. Non-linear time series analysis of EEG in combination with source density estimation techniques and neuro-imaging modalities can significantly develop the objective and differential diagnosis of MDDs.

\section{Acknowledgments}

This study was a part of MSc thesis in Medical Physics and was financially supported by Ahvaz Jundishapur University of Medical Sciences (Grant No.: 940190). 


\section{Conflict of Interest}

The authors declare that there is no conflict of interests regarding the publication of this paper.

\section{References}

ALI, Y., \& Abdolhossein, B. (2014). Brain Computer Interface: Principles, Recent Advances and Clinical Challenges. Orient. J. Comp. Sci. \& Technol., 7(3), 425-442.

Ali, Y., \& Mahmud, N. A. (2014). Neurofeedback treatments for depression disorders: Review of current advances. Orient. J. Comp. Sci. \& Technol., 7(3), 443-452.

Ali, Y., Mahmud, N. A., \& Samaneh, R. (2015). Current Advances in Neurofeedback Techniques for the Treatment of ADHD. Biomedical \& Pharmacology Journal, 8(March Spl Edition), 165-177. http://dx.doi.org/10.13005/bpj/573

Allen, J. J., Urry, H. L., Hitt, S. K., \& Coan, J. A. (2004). The stability of resting frontal electroencephalographic asymmetry in depression. Psychophysiology, 41(2), 269-280. http://dx.doi.org/10.1111/j.14698986.2003.00149.x

Anderson, J. E., Wible, C. G., McCarley, R. W., Jakab, M., Kasai, K., \& Shenton, M. E. (2002). An MRI study of temporal lobe abnormalities and negative symptoms in chronic schizophrenia. Schizophrenia research, 58(2), 123-134. http://dx.doi.org/10.1016/S0920-9964(01)00372-3

Arns, M., Drinkenburg, W. H., Fitzgerald, P. B., \& Kenemans, J. L. (2012). Neurophysiological predictors of non-response to rTMS in depression. Brain stimulation, 5(4), 569-576. http://dx.doi.org/10.1016/ j.brs.2011.12.003

Arns, M., \& Gordon, E. (2014). Quantitative EEG (QEEG) in psychiatry: Diagnostic or prognostic use? Clinical Neurophysiology, 125(8), 1504-1506. http://dx.doi.org/10.1016/j.clinph.2014.01.014

Bares, M., Brunovsky, M., Kopecek, M., Novak, T., Stopkova, P., Kozeny, J., . . Höschl, C. (2008). Early reduction in prefrontal theta QEEG cordance value predicts response to venlafaxine treatment in patients with resistant depressive disorder. European Psychiatry, 23(5), 350-355. http://dx.doi.org/10.1016/j.eurpsy.2008.03.001

Beck, A. T., Steer, R. A., \& Carbin, M. G. (1988). Psychometric properties of the Beck Depression Inventory: Twenty-five years of evaluation. Clinical psychology review, 8(1), 77-100. http://dx.doi.org/10.1016/02727358(88)90050-5

Begić, D., Hotujac, L., \& Jokić-Begić, N. (2001). Electroencephalographic comparison of veterans with combat-related post-traumatic stress disorder and healthy subjects. International Journal of Psychophysiology, 40(2), 167-172. http://dx.doi.org/10.1016/S0167-8760(00)00153-7

Begić, D., Hotujac, L., \& Jokić - Begić, N. (2000). Quantitative EEG in 'positive'and 'negative'schizophrenia. Acta Psychiatrica Scandinavica, 101(4), 307-311.

Begić, D., Popović-Knapić, V., Grubišin, J., Kosanović-Rajačić, B., Filipčić, I., Telarović, I., \& Jakovljević, M. (2011). Quantitative electroencephalography in schizophrenia and depression. Psychiatria Danubina, 23(4.), 355-362.

Bremner, J. D., Vythilingam, M., Vermetten, E., Nazeer, A., Adil, J., Khan, S., . . Charney, D. S. (2002). Reduced volume of orbitofrontal cortex in major depression. Biological psychiatry, 51(4), 273-279. http://dx.doi.org/10.1016/S0006-3223(01)01336-1

Bruder, G. E., Sedoruk, J. P., Stewart, J. W., McGrath, P. J., Quitkin, F. M., \& Tenke, C. E. (2008). EEG alpha measures predict therapeutic response to an SSRI antidepressant: Pre and post treatment findings. Biological psychiatry, 63(12), 1171. http://dx.doi.org/10.1016/j.biopsych.2007.10.009

Carvalho, A., Moraes, H., Silveira, H., Ribeiro, P., Piedade, R. A., Deslandes, A. C., . . Versiani, M. (2011). EEG frontal asymmetry in the depressed and remitted elderly: Is it related to the trait or to the state of depression? Journal of affective disorders, 129(1), 143-148. http://dx.doi.org/10.1016/j.jad.2010.08.023

Cook, I. A., \& Leuchter, A. (2001). Prefrontal changes and treatment response prediction in depression. Paper presented at the Seminars in clinical neuropsychiatry. http://dx.doi.org/10.1053/scnp.2001.21844

Debener, S., Beauducel, A., Nessler, D., Brocke, B., Heilemann, H., \& Kayser, J. (2000). Is resting anterior EEG alpha asymmetry a trait marker for depression? Neuropsychobiology, 41(1), 31-37. http://dx.doi.org/10.1159/000026630 
Deschwanden, A., Karolewicz, B., Feyissa, A. M., Treyer, V., Ametamey, S. M., Johayem, A., . . Stockmeier, C. A. (2011). Reduced metabotropic glutamate receptor 5 density in major depression determined by [11C] ABP688 PET and postmortem study. American Journal of Psychiatry. http://dx.doi.org/10.1176/appi.ajp.2011.09111607

Deslandes, A. C., de Moraes, H., Pompeu, F. A., Ribeiro, P., Cagy, M., Capitão, C., . . . Laks, J. (2008). Electroencephalographic frontal asymmetry and depressive symptoms in the elderly. Biological psychology, 79(3), 317-322. http://dx.doi.org/10.1016/j.biopsycho.2008.07.008

Frodl, T., Schaub, A., Banac, S., Charypar, M., Jäger, M., Kümmler, P., . . . Leinsinger, G. (2006). Reduced hippocampal volume correlates with executive dysfunctioning in major depression. Journal of Psychiatry and Neuroscience, 31(5), 316.

Funk, A. P., \& George, M. S. (2008). Prefrontal EEG asymmetry as a potential biomarker of antidepressant treatment response with transcranial magnetic stimulation (TMS): A case series. Clinical EEG and neuroscience, 39(3), 125-130. http://dx.doi.org/10.1177/155005940803900306

Goldberg, D., Bridges, K., Duncan-Jones, P., \& Grayson, D. (1988). Detecting anxiety and depression in general medical settings. Bmj, 297(6653), 897-899. http://dx.doi.org/10.1136/bmj.297.6653.897

Gordon, E., Palmer, D. M., \& Cooper, N. (2010). EEG alpha asymmetry in schizophrenia, depression, PTSD, panic disorder, ADHD and conduct disorder. Clinical EEG and neuroscience, 41(4), 178-183. http://dx.doi.org/10.1177/155005941004100404

Grin-Yatsenko, V. A., Baas, I., Ponomarev, V. A., \& Kropotov, J. D. (2010). Independent component approach to the analysis of EEG recordings at early stages of depressive disorders. Clinical Neurophysiology, 121(3), 281-289. http://dx.doi.org/10.1016/j.clinph.2009.11.015

He, B., Lian, J., \& Li, G. (2001). High-resolution EEG: A new realistic geometry spline Laplacian estimation technique. Clinical Neurophysiology, 112(5), 845-852. http://dx.doi.org/10.1016/S1388-2457(00)00546-0

Health, N. C. C. f. M. (2010). Depression: The treatment and management of depression in adults (updated edition).

Hunter, A. M., Muthén, B. O., Cook, I. A., \& Leuchter, A. F. (2010). Antidepressant response trajectories and quantitative electroencephalography (QEEG) biomarkers in major depressive disorder. Journal of psychiatric research, 44(2), 90-98. http://dx.doi.org/10.1016/j.jpsychires.2009.06.006

Iosifescu, D. V., Greenwald, S., Devlin, P., Mischoulon, D., Denninger, J. W., Alpert, J. E., \& Fava, M. (2009). Frontal EEG predictors of treatment outcome in major depressive disorder. European Neuropsychopharmacology, 19(11), 772-777. http://dx.doi.org/10.1016/j.euroneuro.2009.06.001

Itil, T. (1982). The significance of quantitative pharmaco-EEG in the discovery and classification of psychotropic drugs. Electroencephalography in drug research. Fischer, Stuttgart, 131-158.

Jaworska, N., Blier, P., Fusee, W., \& Knott, V. (2012). Alpha power, alpha asymmetry and anterior cingulate cortex activity in depressed males and females. Journal of psychiatric research, 46(11), 1483-1491. http://dx.doi.org/10.1016/j.jpsychires.2012.08.003

Johansen-Berg, H., Gutman, D., Behrens, T., Matthews, P., Rushworth, M., Katz, E., . . Mayberg, H. (2008). Anatomical connectivity of the subgenual cingulate region targeted with deep brain stimulation for treatment-resistant depression. Cerebral Cortex, 18(6), 1374-1383. http://dx.doi.org/10.1093/cercor/bhm167

Knott, V., Mahoney, C., Kennedy, S., \& Evans, K. (2001). EEG power, frequency, asymmetry and coherence in male depression. Psychiatry Research: Neuroimaging, 106(2), 123-140. http://dx.doi.org/10.1016/S0925-4927(00)00080-9

Knott, V. J., Telner, J. I., Lapierre, Y. D., Browne, M., \& Horn, E. R. (1996). Quantitative EEG in the prediction of antidepressant response to imipramine. Journal of affective disorders, 39(3), 175-184. http://dx.doi.org/10.1016/0165-0327(96)00003-1

Koolschijn, P., van Haren, N. E., Lensvelt - Mulders, G. J., Pol, H., Hilleke, E., \& Kahn, R. S. (2009). Brain volume abnormalities in major depressive disorder: A meta - analysis of magnetic resonance imaging studies. Human brain mapping, 30(11), 3719-3735. http://dx.doi.org/10.1002/hbm.20801

Korb, A. S., Cook, I. A., Hunter, A. M., \& Leuchter, A. F. (2008). Brain electrical source differences between depressed subjects and healthy controls. Brain topography, 21(2), 138-146. http://dx.doi.org/10.1007/s10548-008-0070-5 
Kwon, J. S., Youn, T., \& Jung, H. Y. (1996). Right hemisphere abnormalities in major depression: Quantitative electroencephalographic findings before and after treatment. Journal of affective disorders, 40(3), 169-173. http://dx.doi.org/10.1016/0165-0327(96)00057-2

Lépine, J.-P. (2000). Epidemiology, burden, and disability in depression and anxiety. The Journal of clinical psychiatry, 62, 4-10; discussion 11-12.

Lépine, J.-P., \& Briley, M. (2011). The increasing burden of depression. Neuropsychiatric disease and treatment, 7 (Suppl 1), 3.

Lieber, A. L. (1988). Diagnosis and subtyping of depressive disorders by quantitative electroencephalography: II. Interhemispheric measures are abnormal in major depressives and frequency analysis may discriminate certain subtypes. Hillside Journal of Clinical Psychiatry.

Lieber, A. L., \& Prichep, L. S. (1988). Diagnosis and subtyping of depressive disorders by quantitative electroencephalography: I. Discriminant analysis of selected variables in untreated depressives. Hillside Journal of Clinical Psychiatry.

Marcus, M., Yasamy, M. T., van Ommeren, M., Chisholm, D., \& Saxena, S. (2012). Depression: A global public health concern. Retrieved February, 7, 2014.

Mientus, S., Gallinat, J., Wuebben, Y., Pascual-Marqui, R. D., Mulert, C., Frick, K., . . W Winterer, G. (2002). Cortical hypoactivation during resting EEG in schizophrenics but not in depressives and schizotypal subjects as revealed by low resolution electromagnetic tomography (LORETA). Psychiatry Research: Neuroimaging, 116(1), 95-111. http://dx.doi.org/10.1016/S0925-4927(02)00043-4

Miller, A. H., Maletic, V., \& Raison, C. L. (2009). Inflammation and its discontents: The role of cytokines in the

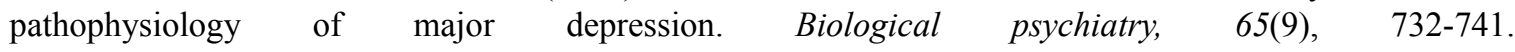
http://dx.doi.org/10.1016/j.biopsych.2008.11.029

Mulert, C., Juckel, G., Augustin, H., \& Hegerl, U. (2002). Comparison between the analysis of the loudness dependency of the auditory N1/P2 component with LORETA and dipole source analysis in the prediction of treatment response to the selective serotonin reuptake inhibitor citalopram in major depression. Clinical Neurophysiology, 113(10), 1566-1572. http://dx.doi.org/10.1016/S1388-2457(02)00252-3

Mulert, C., Juckel, G., Brunnmeier, M., Karch, S., Leicht, G., Mergl, R., . . . Pogarell, O. (2007). Prediction of treatment response in major depression: integration of concepts. Journal of affective disorders, 98(3), 215-225. http://dx.doi.org/10.1016/j.jad.2006.07.021

Norouzi, J., Yadollahpour, A., Mirbagheri, S. A., Mazdeh, M. M., \& Hosseini, S. A. (2016). Predicting renal failure progression in Chronic Kidney Disease using Integrated Intelligent Fuzzy Expert System. Computational and Mathematical Methods in Medicine, vol. 2016. http://dx.doi.org/10.1155/2016/6080814

Olbrich, S., Sander, C., Minkwitz, J., Chittka, T., Mergl, R., Hegerl, U., \& Himmerich, H. (2012). EEG vigilance regulation patterns and their discriminative power to separate patients with major depression from healthy controls. Neuropsychobiology, 65(4), 188-194. http://dx.doi.org/10.1159/000337000

Papakostas, G. I., \& Fava, M. (2008). Predictors, moderators, and mediators (correlates) of treatment outcome in major depressive disorder. Dialogues in clinical neuroscience, 10(4), 439.

Pozzi, D., Golimstock, A., Petracchi, M., García, H., \& Starkstein, S. (1995). Quantified electroencephalographic changes in depressed patients with and without dementia. Biological psychiatry, 38(10), 677-683. http://dx.doi.org/10.1016/0006-3223(94)00371-8

Raison, C. L., Capuron, L., \& Miller, A. H. (2006). Cytokines sing the blues: Inflammation and the pathogenesis of depression. Trends in immunology, 27(1), 24-31. http://dx.doi.org/10.1016/j.it.2005.11.006

Ricardo-Garcell, J., González-Olvera, J. J., Miranda, E., Harmony, T., Reyes, E., Almeida, L., . . . Fernández-Bouzas, A. (2009). EEG sources in a group of patients with major depressive disorders. International Journal of Psychophysiology, 71(1), 70-74. http://dx.doi.org/10.1016/j.ijpsycho.2008.07.021

Roemer, R. A., Shagass, C., Dubin, W., Jaffe, R., \& Siegal, L. (1992). Quantitative EEG in elderly depressives. Brain topography, 4(4), 285-290. http://dx.doi.org/10.1007/BF01135566

Sackeim, H. A., Roose, S. P., \& Burt, T. (2005). Optimal length of antidepressant trials in late-life depression. Journal of clinical psychopharmacology, 25(4), S34-S37. http://dx.doi.org/10.1097/01.jcp.0000170683. 25802.12 
Saletu, B., Anderer, P., \& Saletu-Zyhlarz, G. (2010). EEG topography and tomography (LORETA) in diagnosis and pharmacotherapy of depression. Clinical EEG and neuroscience, 41(4), 203-210. http://dx.doi.org/10.1177/155005941004100407

Snaith, R., Ahmed, S., Mehta, S., \& Hamilton, M. (1971). Assessment of the severity of primary depressive illness: Wakefield self-assessment depression inventory. Psychological Medicine, 1(02), 143-149. http://dx.doi.org/10.1017/S0033291700000064

Sulg, I. (1984). Quantitative EEG as a measure of brain dysfunction. Progress in brain research, 62, 65. http://dx.doi.org/10.1016/S0079-6123(08)62170-6

Teplan, M. (2002). Fundamentals of EEG measurement. Measurement science review, 2(2), 1-11.

Ulrich, G., Renfordt, E., Zeller, G., \& Frick, K. (1984). Interrelation between changes in the EEG and psychopathology under pharmacotherapy for endogenous depression. A contribution to the predictor question. Pharmacopsychiatry, 17(6), 178-183. http://dx.doi.org/10.1055/s-2007-1017433

Von Korff, M., Katon, W., Bush, T., Lin, E. H., Simon, G., Saunders, K., . . Unutzer, J. (1998). Treatment costs, cost offset, and cost-effectiveness of collaborative management of depression. Psychosomatic medicine, 60(2), 143-149. http://dx.doi.org/10.1097/00006842-199803000-00005

Yadollahpour, A. (2014). Applications of Expert Systems in Management of Chronic Kidney Disease: A Review of Predicting Techniques. Orient. J. Comp. Sci. Technol., 7(2), 306-315.

Yadollahpour, A., \& Jalilifar, M. (2014). Seizure Prediction Methods: A Review of the Current Predicting Techniques. Biomedical \& Pharmacology Journal, 7(1), 153-162. http://dx.doi.org/10.13005/bpj/466

Zoon, H. F., Veth, C., Arns, M., Drinkenburg, W., Talloen, W., Peeters, P. J., \& Kenemans, J. (2013). EEG alpha power as an intermediate measure between brain-derived neurotrophic factor Val66Met and depression severity in patients with major depressive disorder. Journal of Clinical Neurophysiology, 30(3), 261-267. http://dx.doi.org/10.1097/WNP.0b013e3182933d6e

\section{Copyrights}

Copyright for this article is retained by the author(s), with first publication rights granted to the journal.

This is an open-access article distributed under the terms and conditions of the Creative Commons Attribution license (http://creativecommons.org/licenses/by/3.0/). 